\title{
Ludwig's Angina: Clinical Profile and Microbiology with Antibiotic Resistance and Sensitivity at Referral Hospital
}

\author{
Muhamad Saifuddin*, Sahudi \\ Department of General Surgery, Head and Neck Division, \\ Faculty of Medicine Airlangga University, Surabaya, Indonesia \\ *Corresponding author details: Muhamad Saifuddin; doktersaif@gmail.com
}

\begin{abstract}
Objective: To assess the distribution of sex and age, comorbidity factors, etiology, management protocol, isolated organisms, antibiotic resistance and sensitivity.

Material and Methods: Retrospective observational study based on medical records in 2007 - 2016 and microbiological examination data from 2012 - 2016.

Results: The proportion of males was greater than females 1.8 (71): 1 (29). Mean age $41 \pm$ SD 16.99. The most comorbidity diagnoses were type 2 diabetes mellitus (DM) 24.5\% (27) and the most complications were sepsis $21.8 \%$ (24). The most common etiology was odontogenic infection $92 \%$. Patients underwent drainage incisions and were treated with empiric ceftriaxone and metronidazole for an average of 7 days of treatment. Outcomes recovery were $93.7 \%(102)$ and were death $5.4 \%$ (6). The three most common types of bacteria as the etiology were Enterobacter spp. 32\% (9), Streptococcus spp. 25\% (7), Staphylococcus spp. 18\% (5). Ceftriaxone showed considerable resistance to gram-negative bacteria as well as to gram-positive bacteria (Streptococcus spp.). Conclusion: The ratio of male to female was 1.8:1 and odontogenic infection was $92 \%$. DM increases the risk of complications of sepsis and prolongs the day of care. A drainage incision should be performed immediately. Gram negative bacteria were the most common bacteria found. The efficacy of using ceftriaxone as empirical therapy needs to be reviewed.
\end{abstract}

Keywords: Ludwig's Angina; clinical profile; microbiology; odontogenic infection

\section{INTRODUCTION}

Ludwig's angina was first described by Wilhelm Frederick von Ludwig as a fast-processing cellulitis in the region of the submandibular gland that spreads through anatomical contiguity without leading to abscess formation. [1-2] The spread of odontogenic infections accounts for $57 \%$ of deep neck abscesses. With the potential for spread of infection to the intrapleural space and mediastinal tissue, the mortality rate for mediastinitis ranges from 17 - 50\%. Death is usually caused by sepsis.[3] In addition, airway obstruction is a serious complication and requires airway management such as tracheostomy. [4] In the pre-antibiotic era, Ludwig's angina mortality was up to $50 \%$. Currently, aggressive management with airway protection, intravenous antibiotics and surgical intervention can significantly reduce mortality by less than $10 \%$.[5-8]

Although the microbiology of Ludwig's Angina is polymicrobial, the most common bacteria were Streptococcus, Staphylococcus, and Bacteroides species. In cases of odontogenic infection, Streptococcus viridans and Eschericia coli were the most usual culture.[9-10]

Even though medical science has advanced, Ludwig's Angina cases were still quite a lot in referral hospitals. Various kinds of etiologies and comorbid diseases have been studied in several countries, but this research was still rarely carried out in Indonesia, especially in Surabaya, East Java, Indonesia.

\section{PATIENTS AND METHODS}

We conducted a retrospective observational study based on the medical records of patients with Ludwig's Angina Head and Neck Surgery during January 2007 - December 2016 and data from microbiological examinations with resistance and sensitivity data during January 2012 - December 2016. Data for 2007 - 2011 were not obtained because was lost. These data were obtained from the medical records division and the microbiology division of Dr. Sutomo Hospital, Surabaya, Indonesia. The study had been approved by the hospital ethics No. 0656/106/4/IV/2021.

We conducted a total sampling of all medical record data and microbiological examination data of Ludwig's Angina patients during this period. The data were patient demographics, etiology, comorbid diseases, complications, surgery, duration of treatment, data on isolated bacteria, antibiotic resistance and sensitivity.

\section{RESULTS}

This study shows that the proportion of male to female ratios is 1.8 (71): 1 (39). More patients suffer under the age of 60 both male and female. The average age of the patient 41.

TABLE 1: Age and Gender Distribution

\begin{tabular}{ccc}
\hline Usia & Male & Female \\
\hline$<60$ & 61 & 31 \\
$>60$ & 10 & 8 \\
\hline
\end{tabular}


The most common etiology was dental caries or odontogenic infection of the lower 2 nd and 3rd molars. $92 \%$ of the causes were odontogenic infections. This study found the most comorbid diseases, namely Diabetes Mellitus type 2 as much as $24.5 \%$ (27) and the diagnosis of complications, namely sepsis $21.8 \%$ (24).

All patients underwent incision drainage. Tracheostomy was performed only if the patient had signs of impending airway obstruction. Empirical antibiotic therapy using antibiotics ceftriaxone and metronidazole. The average number of treatment days was 7 days. The outcome of patients living was $93.7 \%$ (102) and death was 5.4\% (6).

The results of bacterial culture during January 2012December 2016 were 55 samples. There were 33 sample examinations showing 18 bacterial strains and the remaining 22 examinations showing sterile results. The most bacteria were gram-negative bacteria as much as $57 \%$ and gram-positive bacteria as much as $43 \%$. The three most common types of bacteria as the etiology were Enterobacter spp. 32\% (9), Streptococcus spp. 25\% (7), Staphylococcus spp. 18\% (5).

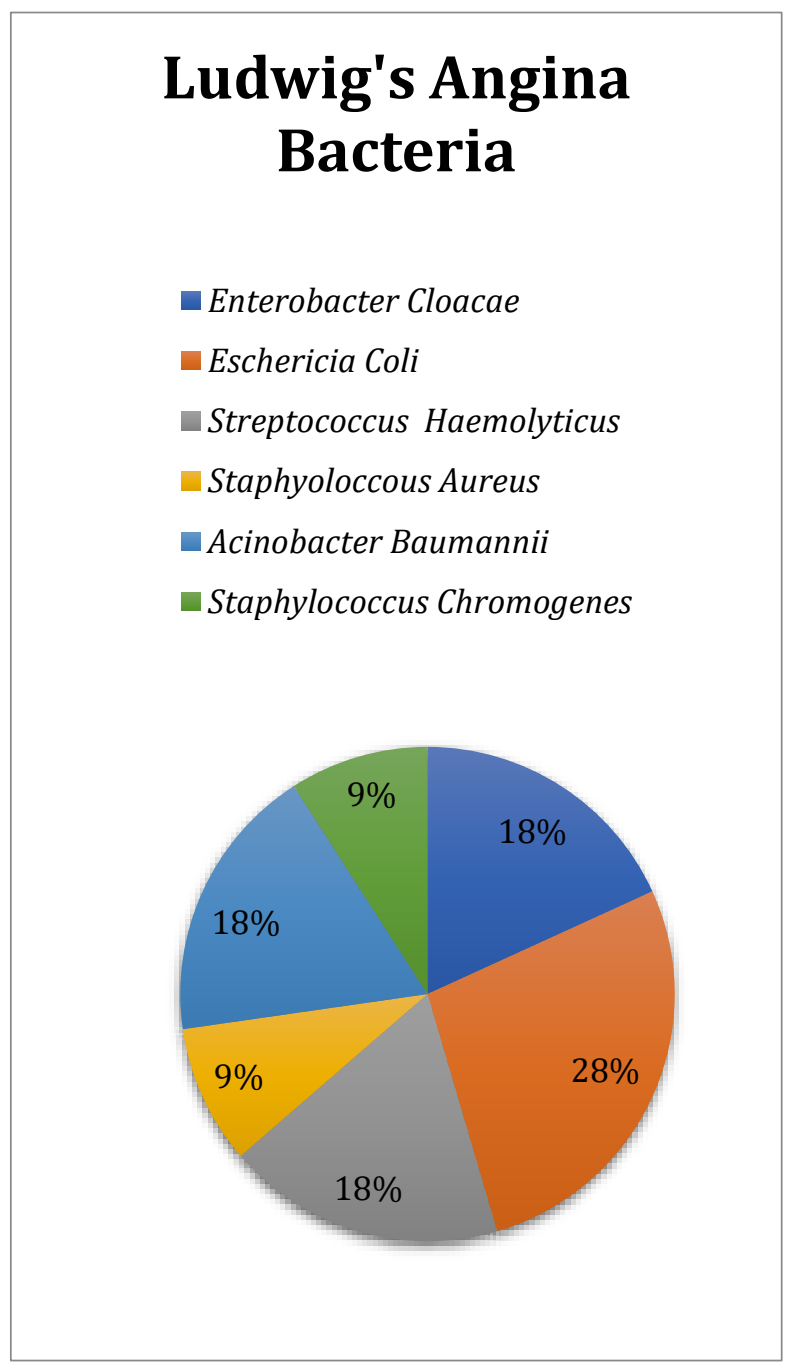

FIGURE 1: Distribution of isolated bacteria from infected tissues of Ludwig's Angina.
TABLE 2: Overview of Antibiotic Resistance and Sensitivity to Enterobacter spp.

\begin{tabular}{|c|c|c|}
\hline Jenis Antibiotik & $\begin{array}{l}\text { Percent (n) } \\
\text { Resistant }\end{array}$ & $\begin{array}{l}\text { Percent (n) } \\
\text { Sensitive }\end{array}$ \\
\hline Amikacin & 0 & $100(5)$ \\
\hline Imipenem & 0 & $100(4)$ \\
\hline Meropenem & 0 & $100(3)$ \\
\hline $\begin{array}{l}\text { Cefoperazone } \\
\text { sulbactam }\end{array}$ & 0 & $100(2)$ \\
\hline Ertapenem & $33,3(2)$ & $66,7(4)$ \\
\hline Gentamycin & $50(3)$ & $50(3)$ \\
\hline Fosfomycin & $50(1)$ & $50(1)$ \\
\hline Tobramycin & $57,2(4)$ & $42,8(3)$ \\
\hline Levofloxacin & $60(3)$ & $40(2)$ \\
\hline Ciprofloxacin & $66,7(4)$ & $33,3(2)$ \\
\hline $\begin{array}{l}\text { Pepiracillin } \\
\text { Tazobactam }\end{array}$ & $66,7(2)$ & $33,3(1)$ \\
\hline Cotrimoxazole & $71,4(5)$ & $28,6(2)$ \\
\hline Cefotaxim & $66,3(2)$ & $33,3(1)$ \\
\hline $\begin{array}{l}\text { Amoxcillin- } \\
\text { Clavulanic Acid }\end{array}$ & $80(4)$ & $20(1)$ \\
\hline Ampicillin & $80(4)$ & $20(1)$ \\
\hline $\begin{array}{l}\text { Ampicillin } \\
\text { Sulbactam }\end{array}$ & $75(3)$ & $25(1)$ \\
\hline Astreonam & $83,3(5)$ & $16,7(1)$ \\
\hline Ceftazidime & $20(4)$ & $20(1)$ \\
\hline Ticarcilline $\mathrm{C}$ & $100(1)$ & 0 \\
\hline Tigecycline & $100(2)$ & 0 \\
\hline Cephazoline & $100(3)$ & 0 \\
\hline Tetracyclin & $100(3)$ & 0 \\
\hline Ceftriaxon & $100(4)$ & 0 \\
\hline
\end{tabular}

TABLE 3: Overview of Antibiotic Resistance and Sensitivity to Streptococcus spp.

\begin{tabular}{lll}
\hline Jenis Antibiotik & $\begin{array}{l}\text { Percent (n) } \\
\text { Resistant }\end{array}$ & $\begin{array}{l}\text { Percent (n) } \\
\text { Sensitive }\end{array}$ \\
\hline Levofloxacin & 0 & $100(7)$ \\
Chloramphenicol & 0 & $100(5)$ \\
Erythromycin & 0 & $100(5)$ \\
Clindamcyin & 0 & $100(4)$ \\
Vancomycin & 0 & $100(4)$ \\
Linezolid & 0 & $100(3)$ \\
Cotrimoxazole & $25(2)$ & $75(6)$ \\
Penicillin G & $38,6(2)$ & $71,4(5)$ \\
Fosfomycin & $33,3(2)$ & $66,7(4)$ \\
Oxacillin & $40(2)$ & $60(3)$ \\
Ampicillin & $50(2)$ & $50(2)$ \\
Ceftriaxon & $33,3(1)$ & $66,7(2)$ \\
Clindamycin & $50(1)$ & $50(1)$ \\
Cefoxcitin & $100(2)$ & 0 \\
Gentamycin & $100(7)$ & 0 \\
\hline
\end{tabular}


Table 4: Overview of Antibiotic Resistance and Sensitivity to Staphylococcus spp.

\begin{tabular}{lll}
\hline Jenis Antibiotik & Resistant & Sensitive \\
\hline Fosfomycin & 0 & $100(2)$ \\
Vancomycin & 0 & $100(1)$ \\
Daptomycin & 0 & $100(1)$ \\
Tetracyclin & $50(2)$ & $50(2)$ \\
Chloramphenicol & $50(1)$ & $50(1)$ \\
Clindamcyin & $50(1)$ & $50(1)$ \\
Clindamycin & $50(1)$ & $50(1)$ \\
Meropenem & $50(1)$ & $50(1)$ \\
Erythromycin & $50(1)$ & $50(1)$ \\
Cotrimoxazole & $66,7(2)$ & $33,3(1)$ \\
Ampicillin & $66,7(2)$ & $33,3(1)$ \\
Sulbactam & $66,7(2)$ & $33,3(1)$ \\
Gentamycin & $66,7(2)$ & $33,3(1)$ \\
Levofloxacin & $66,7(2)$ & $33,3(1)$ \\
Moxifloxacin & $75(3)$ & $25(1)$ \\
Oxacillin & $100(1)$ & 0 \\
Gatifloxacin & $100(1)$ & 0 \\
Norfloxacin & $100(1)$ & 0 \\
Quinopristin- & $100(2)$ & 0 \\
dalfopristin & $100(3)$ & 0 \\
Penicillin G & & \\
Ampicillin & & 50 \\
\hline & 50 & \\
\hline
\end{tabular}

Gram-negative bacteria were resistant to Ceftriaxone, Tetracycline, Cefazoline, Levofloxacin, Chloramphenicol, Fosfomycin, but otherwise sensitive to Amikacin, Imipenem, Meropenem, and Cefoperazone Sulbactam.

Gram positive bacteria were resistant to Gentamicin Cefoxitin, Ampicillin, Penicillin G, but otherwise sensitive to Levofloxacin, Chloramphenicol, Erythromycin, Vancomycin, Linezolid.

Cephalosporin, penicillin, monobactam which were subclasses of beta-lactam antibiotics showed a significant resistance rate.

\section{DISCUSSION}

Ludwig's Angina in the pre-antibiotic era with a high mortality rate of $50 \%$, but now the mortality rate has dropped to $8-10 \%$. [5-8] In the span of 10 years (2007 2016), the mortality rate of Ludwig's Angina at Dr. Hospital. Sutomo Surabaya as much as $5.4 \%$. This figure is already below the current world death rate which is still at 10\%.[5] The proportion of male patients compared to female patients with a ratio of 1.8: 1 . The average age of patients is $41 \pm$ SD 16.99. More sufferers were in productive age which has implications for their productivity at work.

Diabetes Mellitus is an important comorbid condition in sepsis because of its high prevalence.[11] Diabetic patients are generally believed to be more prone to infections than the general population. Diabetes mellitus exacerbates the decline. There are many functions of the body organs and cause immune disorders. [6,12-13] The most of Ludwig's Angina patients who come then die in the hospital are patients with comorbidity Diabetes Mellitus who may have been immunocompromised and came in a septic condition since they first came to the hospital. Systemic diseases such as diabetes mellitus increase the severity of Ludwig's Angina patients. Mathew, G et al., 5 years retrospective study in Punjab, demonstrated the results of a univariate evaluation of patients at risk of life with comorbid diabetes mellitus (p: 0.02).[4] Study Botha, Andrew et al in Pretoria, South Africa, involving 93 patients with 73.1\% odontogenic causes and the most comorbidity diseases with diabetes mellitus 21 (22.6\%).[14]

Incision drainage was performed on all patients. Tracheostomy was performed only if the patient had signs of impending airway obstruction. Aggressive surgery accompanied by empiric antibiotics with ceftriaxone and metronidazole reduced the incidence of patients falling into sepsis.

Microbiological examination of 55 patients in $2012-2016$ showed 33 examinations with a description of 18 isolated types of bacteria, while 22 examinations showed sterile results or no bacterial isolation was obtained. This may be because the pus being evaluated is sterile pus. Microbiological examination should involve taking tissue other than the pus being examined for optimal results. It is possible to culture deep tissue specimens for wounds because pus swab culturing is associated with a high risk of missing pathogens, especially Gram-negative bacteria.[15]

Most isolated microorganisms from culture results were Enterobacter spp. 32\% (9), Streptococcus spp. 25\% (7), Staphylococcus spp. $18 \%$ (5). Although microbiology Ludwig's Angina is usually polymicrobial with many gram positive, gram negative, aerobic/anaerobic organisms. This study showed 23 results of microbial culture with antibiotic resistance and sensitivity. All culture results showed aerobic bacteria and no anaerobic bacteria culture results were obtained. The results of no anaerobic bacterie happenned because of the problem of transporting the sample material which was not suitable for the examination of anaerobic bacteria. A total of 18 bacterial strains were isolated in culture examination. Gram negative bacteria as much as $57 \%$ and gram-positive bacteria as much as $43 \%$. Enterobacter spp. is the most common bacteria as much as $32 \%$, followed by Streptococcus spp. $25 \%$ and Staphylococcus spp. $18 \%$.

Lin Ye et al's study on 100 patients showed that the most common organism in Ludwig's angina was Klebsiella spp. $17.54 \%$, Clostridium tertium $14.03 \%$, Staphylococcus Aureus 14.03\%, Actinomyces odontolyticus 12.28\%, Lactobacillus spp. 8.7\%, Peptostreptococcus sp. 7.01\%, E.Coli 5.26\%, Streptococcus sp. 4.38\%, Streptococcus milleri 3.50\%, Bacteriodes melaninogenicus $3.50 \%$, Pesudomonas aeruginosa $3.50 \%$ and Streptococcus mutans $1.753 \%$. and Fusobacterium nucleatum 0.877\%.[16] The most common aerobic bacterial organisms were Klebsiella spp. 17.54\%, Staphylococcus aureus $14.03 \%$, Streptococcus sp 4.38\%, Pseudonomans aeurginosa $3.50 \%$ and Streptococcus mutans $2.63 \%$.

Amit Shah et al's study on 100 patients showed that isolated aerobic bacteria Streptococcus viridans 47\%, Staphylococcus aureus 16\%, Klebsiella pneumonia 11\%, Pseudomonas aeruginosa 6\%, Staphylococci (coagulase ve) 6\%, Escherichia coli 3\%, -ve) and Staphylococci (coagulase+ve) 2\%.[17]

Inderdeep Singh Walia et al's study on 42 patients showed that the most isolated bacteria were S. aureus $17.50 \%$. This may be due to contamination of the culture with the skin during extra-oral drainage. This contradicts the literature which states that predominant was Streptococcus viridans. The highest to lowest gram-negative findings 
were Klebsiella 10\%, E. Coli 10\%, and Pseudomonas aeruginosa 5\%. Goldberg, Sabiston and Gold reported the isolation of gram-negative bacilli such as Klebsiella, E. Coli, and Chromobacterium violaceus.[18]

In this study, gram-negative bacteria were resistant to Ceftriaxone, Tetracycline, Cefazoline, Levofloxacin, Chloramphenicol, Fosfomycin, however they were sensitive to Amikacin, Imipenem, Meropenem, and Cefoperazone Sulbactam. Gram positive bacteria were resistant to Gentamicin, Cefoxitin, Ampicillin, Penicillin G, however they were sensitive to Levofloxacin, Chloramphenicol, Erythromycin, Vancomycin, Linezolid.

Cephalosporin, penicillin, monobactam which were subclasses of beta-lactam antibiotics showed a significant resistance rate. On the other hand, the Carbapenem group showed a good sensitivity value to gram negative. In addition, the Macrolide group such as Amikacin showed good sensitivity values for gram-negative and Vancomycin had good sensitivity values for gram-positive. The fluoroquinolone group, namely Levofloxacin, showed good sensitivity values in gram-positive but showed resistance in some gram-negatives.

Ceftriaxone which was a drug in the empirical therapy of Ludwig's angina patients showed a number of significant resistance findings between gram-negative bacteria and gram-positive bacteria (streptococcus spp). Although the number of findings was not large enough, it was an important noted of ceftriaxone so that its use was reevaluated by consulting a microbiologist.

\section{CONCLUSION}

Immediate treatment of Ludwig's angina patients with surgical incisions with surgical drainage incisions, airway management and non-operative measures such as empiric antibiotics, analgesics, nutritional support, identification of comorbid diseases such as diabetes mellitus were comprehensive steps that must be taken to obtain optimally outcomes.

Collecting cultures from pus should involve removing tissue to avoid sterile examination results. Special examinations for anaerobic bacteria need to involve a microbiologist directly during sampling so that the samples taken were appropriate and transported under the right conditions so that anaerobic bacteria were isolated.

Drugs in the subclasses of beta-lactam antibiotics showed a significant resistance value. Other classes of antibiotics such as Fluoroquinolones also show the same resistance results. Macrolide and Carbapenem groups were choices with good sensitivity values.

\section{REFERENCE}

[1] Hupp JR, Ellis E, Tucker MR, editors. Contemporary Oral and Maxilofacial Surgery. 6th edition ed. Misouri: Elsevier; 2014.

[2] De Melo TAF, Rucker T, do Carmo MPD, Irala LED, Salles AA. Ludwig's angina: diagnosis and treatment. RSBO. [Literature Review Article]. 2013 April-Juni 10(2):172-5.

[3] Weise H, Naros A, Weise C, Reinert S, Hoefert S. Severe odontogenic infections with septic progress - a constant and increasing challenge: a retrospective analysis. BMC Oral Health. 2019 2019/08/02;19(1):173.

[4] Lalwani AK, editor. Current Diagnosis \& Treatment. Otolaryngology Head and Neck Surgery. Second Edition New York: Mc Graw Hill; 2008.
[5] Simion L, Dumitru S. Phlegmon of the oral floor. Contradictions in diagnosis and treatment. The Moldovan Medical Journal. 2018;61(1):42-8.

[6] Miloro M, editor. Peterson's Principles of Oral and Maxillofacial Surgery. Second Edition ed. London: BC Decker Inc; 2004.

[7] Wray D, Stenhouse D, Lee D, Clark AJE, editors. Textbook General and Oral surgery. 1 ed. Edinburgh: Churcill Livingstone. An imprint of Elsevier Science Limited; 2003.

[8] Lore JM, Medina JE. An Atlas of Head and Neck Surgery. Incision and Drainage of Abscessesof the Neck. 4th Edition ed. Phyladelphia 2005. p. 854-5.

[9] Braimah R, Taiwo A, Ibikunle A. Ludwig's angina: Analysis of 28 cases seen and managed in Sokoto, Northwest Nigeria. Saudi Surgical Journal. [Original Article]. 2016 May 1, 2016;4(2):77-83.

[10] Razib SFA, Banerjee S, Uddin MM, Shameeussalam K, Rahman MM. Distribution and Determinants of Ludwig's Angina: Experience of 30 Cases in Bangladesh. Journal of Current and Advance Medical Research. 2016;3(1):16-21.

[11] Iwashyna T, Netzer G, Langa K, Cigolle C. Spurious Inferences about Long-Term Outcomes: The Case of Severe Sepsis and Geriatric Conditions. American journal of respiratory and critical care medicine. 2012; 185:835-41.

[12] Donnelly J, Nair S, Griffin R, Baddley J, Safford M, Wang $\mathrm{H}$, et al. Diabetes and Insulin Therapy are associated with Increased Risk of Hospitalization for Infection but not Mortality: A Longitudinal Cohort Study. Clinical infectious diseases: an official publication of the Infectious Diseases Society of America. 2016;64.

[13] Esper AM, Moss M, Martin GS. The effect of diabetes mellitus on organ dysfunction with sepsis: an epidemiological study. Critical care (London, England). 2009;13(1): R18-R.

[14] Botha A, Jacobs F, Postma C. Retrospective analysis of etiology and comorbid diseases associated with Ludwig's Angina. Ann Maxillofac Surg. 2015;5(2):168-73. doi: 10.4103/2231-0746.175758.

[15] Huang Y, Cao Y, Zou M, Luo X, Jiang Y, Xue Y, et al. A Comparison of Tissue versus Swab Culturing of Infected Diabetic Foot Wounds. International Journal of Endocrinology. 2016 2016/03/30; 2016:8198714.

[16] Ye L, Liu Y-B, Geng A-L. Microbiological examination to investigate the differences in microorganisms and antibiotic sensitivity of head and neck space infections. Biomedical Research. 2017 June 2, 2016;28(1):290-4.

[17] Shah A, Ramola V, Nautiyal V. Aerobic microbiology and culture sensitivity of head and neck space infection of odontogenic origin. National Journal of Maxillofacial Surgery. 2016 Jan-Jun;7(1):56-61.

[18] Walia IS, Borle RM, Mehendiratta D, Yadav AO. Microbiology and Antibiotic Sensitivity of Head and Neck Space Infections of Odontogenic Origin. Journal of Maxillofacial \& Oral Surgery. 2014;13(1):16-21. 


\section{AUTHOR'S CONTRIBUTIONS}

Each named author has substantially contributed to the underlying research and has approved the final manuscript.

\section{CONFLICT OF INTEREST}

This manuscript has not been published and is not under consideration for publication elsewhere. We have no funding and none of the authors have any conflict of interest, financially or otherwise. 